\title{
Anticoagulation in a Patient With Mechanical Prosthetic Valves and Calcific Uremic Arteriolopathy on Warfarin
}

\author{
Megan C. Smith ${ }^{1}$, Evan Gleaves ${ }^{2}$, Aniruddha Singh ${ }^{1}$, Muhammad Akbar ${ }^{1}$ \\ 1. Cardiology, University of Kentucky, Bowling Green, USA 2. Internal Medicine, University of Kentucky, Bowling Green, \\ USA
}

Corresponding author: Megan C. Smith, megtail04@gmail.com

\begin{abstract}
Calciphylaxis, or calcific uremic arteriolopathy (CUA), is a rare vascular calcific disease that is most often associated with renal dysfunction and warfarin, particularly end-stage renal disease (ESRD). This condition causes debilitatingly painful skin lesions, oftentimes plaques, throughout areas of cutaneous and subcutaneous adiposity. The progression of these lesions to black eschar with ulceration is the hallmark of CUA. In this report, we present the case of a Caucasian female with a past medical history of nephrogenic systemic fibrosis (NSF), ESRD, and mechanical aortic and mitral valves, anticoagulated with warfarin, who developed CUA. In the setting of mechanical prosthetic valves, vitamin K antagonists (VKA) and aspirin are the only evidence-based antithrombotic therapies. This case presents challenging decision-making when managing anticoagulant therapy in the absence of applicable guidelines.
\end{abstract}

Review began 03/21/2021 Review ended 03/28/2021 Published 03/30/2021

() Copyright 2021

Smith et al. This is an open access article distributed under the terms of the Creative Commons Attribution License CC-BY 4.0., which permits unrestricted use, distribution, and reproduction in any medium, provided the original author and source are credited.
Categories: Cardiac/Thoracic/Vascular Surgery, Cardiology, Nephrology

Keywords: calcific uremic arteriolopathy, prosthetic heart valve, oral anticoagulation, bridging anticoagulation

\section{Introduction}

Calcific uremic arteriolopathy (CUA) is a rare disease with the first known description in 1855, which is associated with renal dysfunction and warfarin, particularly end-stage renal disease (ESRD). CUA has an incidence rate of 3.49 per 1000 patient-years. This is elevated to 6.24 per 1000 patients-years in warfarin users [1]. There is evidence that the cause of increased incidence of calciphylaxis in warfarin users is secondary to the vitamin K-dependent proteins, matrix Gla protein (MGP), and growth arrest-specific gene 6, which are carboxylated in the vasculature by vitamin $\mathrm{K}$ and thus inhibited by warfarin [2]. MGP is produced in bone and vascular smooth muscle and prevents vascular calcification. A defect in the MGP gene causes Keutel syndrome, which is associated with extensive soft tissue and vascular calcification [3].

\section{Case Presentation}

The patient is a Caucasian female who presented with the chief complaint of severe burning pain under her breast for roughly one month duration. The pain was located in the right and left upper quadrants. She described it as burning and sensitive to the touch, and " $10 / 10$ " with palpation. Her skin had become progressively more discolored and tough. On physical exam, there were extensive hard erythematous lesions bilaterally extending from under the breast to the mid abdomen (Figures 1,2). 


\section{Cureus}

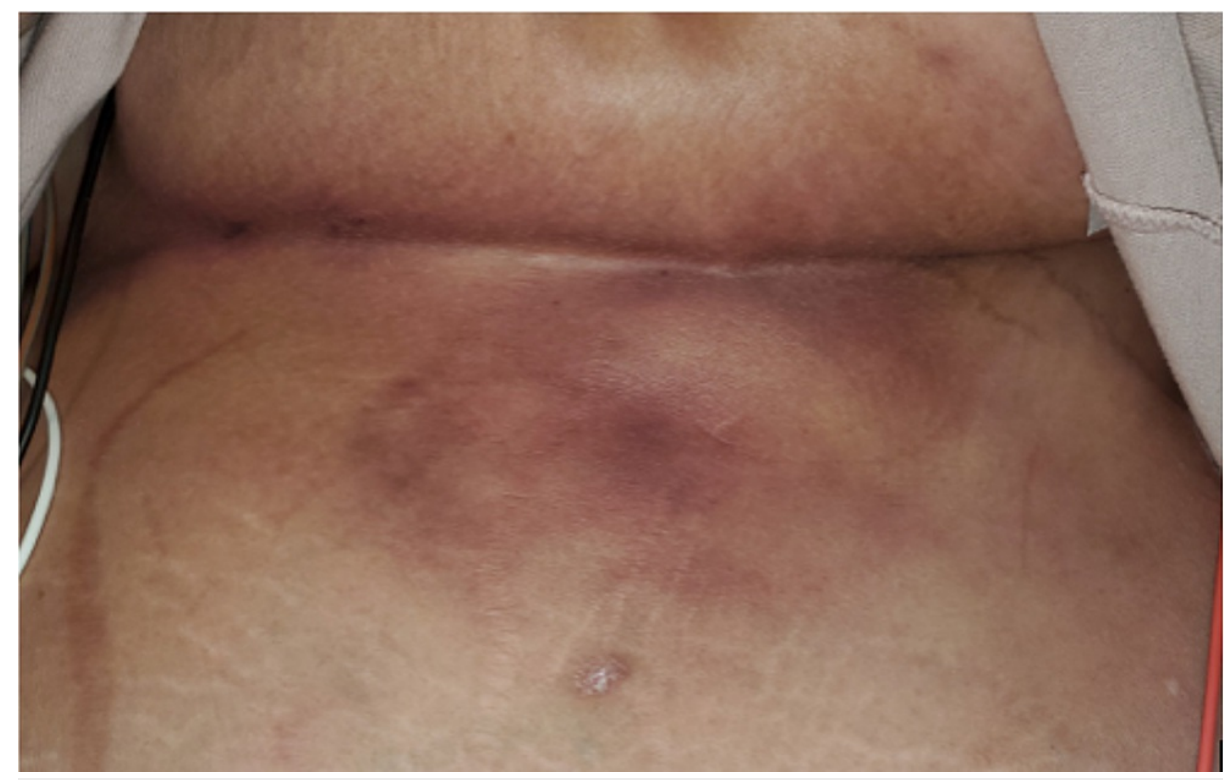

FIGURE 1: CUA lesion under left breast of patient extending caudally to the abdomen.

CUA: calcific uremic arteriolopathy

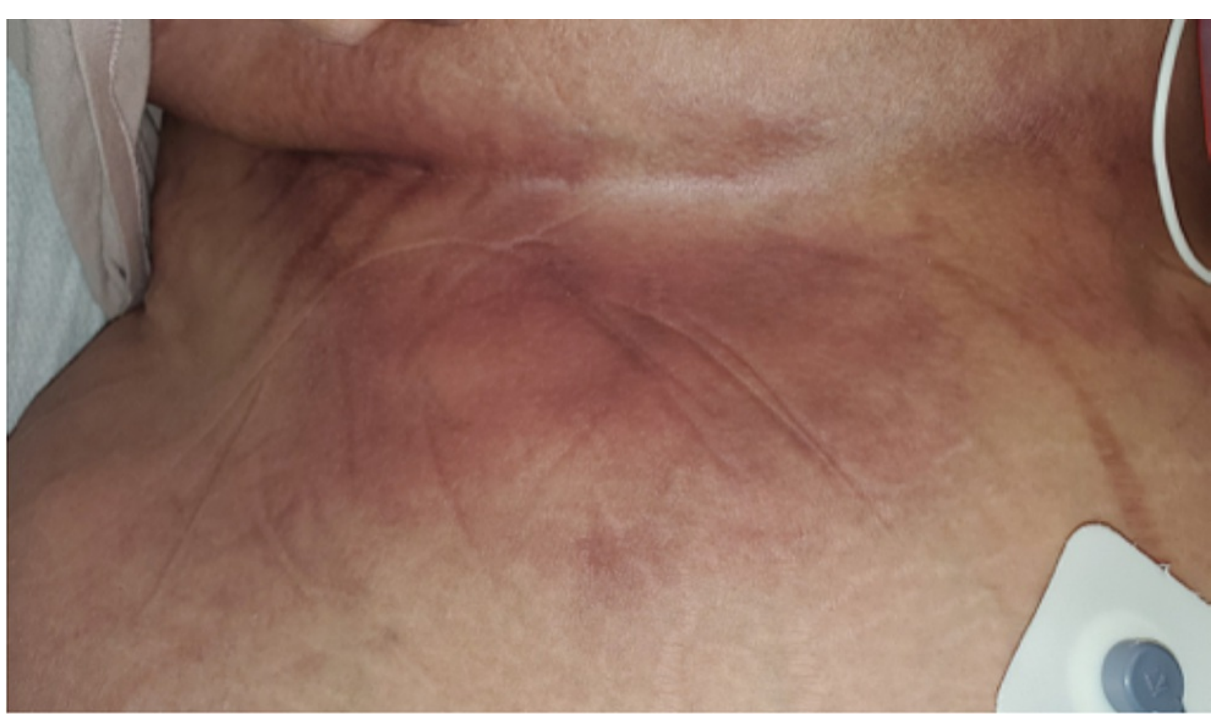

FIGURE 2: CUA lesion under right breast of patient extending caudally to the abdomen.

CUA: calcific uremic arteriolopathy.

Past medical history was significant for ESRD on dialysis for the past 25 years, kidney transplant in 1996 complicated by rejection, nephrogenic systemic fibrosis, $19 \mathrm{~mm}$ St. Jude mechanical aortic valve, and $27 \mathrm{~mm}$ St. Jude mechanical mitral valve replacements in 2014 due to severe mitral stenosis and moderate aortic stenosis due to extensive calcification, and leadless pacemaker after an atrioventricular (AV) node ablation in 2018. Pertinent medications included warfarin $4 \mathrm{mg}$ daily, which she had been taking for over 10 years.

Transthoracic echocardiogram revealed a preserved ejection fraction of 55-60\%, well-seated mechanical prosthetic valves in the aortic and mitral positions with normal peak and mean gradients.

Given her use of warfarin and exquisitely painful skin lesions, warfarin-induced skin necrosis was considered. Her history was significant for a large number of risk factors for CUA, making it a likely explanation. To distinguish between warfarin-induced skin necrosis and CUA, it is important to note the 
time of onset of warfarin and the response to cessation. Warfarin-induced skin necrosis usually occurs within the first few days of initiation and rapidly clears with cessation. CUA can occur much later and does not resolve quickly with cessation.

Our patient had been taking warfarin for over 10 years, making CUA more likely. Dermatology confirmed the diagnosis of CUA via physical examination and history. She was started on a regimen of sodium thiosulfate $25 \mathrm{~g}$ as tolerated during dialysis. Due to her atrial fibrillation and mechanical valves, the continuation of anticoagulation was of paramount importance. Warfarin was held, and she was transitioned to renally dosed enoxaparin to be continued until resolution of CUA with anti-Xa monitoring (target 0.6-1.1 IU/mL). The initial dose was $100 \mathrm{mg}$ of enoxaparin daily (1 mg/kg), however, anti-Xa levels remained subtherapeutic at 0.4-0.5 IU/mL. Enoxaparin dose was subsequently increased to $110 \mathrm{mg}$ daily after three days, resulting in the achievement of therapeutic levels.

On hospital discharge, the painful purpura were improving but not resolved. Sodium thiosulfate $25 \mathrm{~g}$ with hemodialysis will continue until the purpura have resolved. Close follow-up with her primary care physician was scheduled soon after hospital discharge with plans to continue enoxaparin and anti-Xa monitoring weekly until CUA resolves.

\section{Discussion}

In the setting of mechanical prosthetic valves, the 2020 updated AHA guidelines for the management of patients with valvular heart disease recommend vitamin K antagonists (VKA) as the only evidence-based therapy for anticoagulation [4]. Given our patient's diagnosis of CUA and warfarin's association with the condition, there was an absence of applicable guidelines for anticoagulation while her CUA resolved. The complete discontinuation of her anticoagulation would represent a significant risk given her multiple indications for anticoagulation: atrial fibrillation (CHA2DS2-VASc score of 6), mechanical mitral and aortic valves, and prior stroke. Direct oral anticoagulants have been used with success in patients with CUA [5], however, these agents are also contraindicated in advanced renal failure with the exception of apixaban. Apixaban showed a lower risk of bleeding compared to warfarin in patients with renal disease excluding ESRD [6]. Direct thrombin inhibitors such as dabigatran are indicated as anticoagulation for atrial fibrillation but are contraindicated in patients with mechanical heart valves due to increased risk of thromboembolic and bleeding complications compared to warfarin [7]. There is limited evidence that heparin is a viable substitution for anticoagulation in patients with CUA on warfarin [8]. While there have been no large-scale trials indicating unfractionated heparin or low-molecular-weight heparin (LMWH) for patients with mechanical heart valves, there is a class I recommendation for LMWH when anticoagulation with warfarin must be interrupted $[9,10]$. In light of this, we believe that our patient was best served by the selection of the LMWH enoxaparin for anticoagulation until warfarin can be continued.

\section{Conclusions}

CUA is a rare disease often associated with ESRD and warfarin. Management decisions are further complicated when the patient has mechanical prosthetic valves. Given the rarity of this scenario, there are no specific guidelines. Extrapolating from the most recent guidelines for interrupting anticoagulation in a patient with mechanical prosthetic valves, we managed this patient with renally dosed enoxaparin until we can consider resuming warfarin again.

\section{Additional Information \\ Disclosures}

Human subjects: Consent was obtained or waived by all participants in this study. Conflicts of interest: In compliance with the ICMJE uniform disclosure form, all authors declare the following: Payment/services info: All authors have declared that no financial support was received from any organization for the submitted work. Financial relationships: All authors have declared that they have no financial relationships at present or within the previous three years with any organizations that might have an interest in the submitted work. Other relationships: All authors have declared that there are no other relationships or activities that could appear to have influenced the submitted work.

\section{References}

1. Nigwekar SU, Zhao S, Wenger J, Hymes JL, Maddux FW, Thadhani RI, Chan KE: A nationally representative study of calcific uremic arteriolopathy risk factors. J Am Soc Nephrol. 2016, 27:3421-9. 10.1681/ASN.2015091065

2. Danziger J: Vitamin K-dependent proteins, warfarin, and vascular calcification. Clin J Am Soc Nephrol. 2008, 3:1504-10. 10.2215/CJN.00770208

3. Meier M, Weng LP, Alexandrakis E, Rüschoff J, Goeckenjan G: Tracheobronchial stenosis in Keutel syndrome. Eur Respir J. 2001, 17:566-9. 10.1183/09031936.01.17305660

4. Otto CM, Nishimura RA, Bonow RO, et al.: 2020 ACC/AHA Guideline for the Management of Patients With Valvular Heart Disease: A report of the American College of Cardiology/American Heart Association Joint Committee on Clinical Practice Guidelines. Circulation. 2021, 143:e72-e227.

10.1161/CIR.0000000000000923 


\section{Cureus}

5. King BJ, El-Azhary RA, McEvoy MT, Shields RC, McBane RD, McCarthy JT, Davis MDP: Direct oral anticoagulant medications in calciphylaxis. Int J Dermatol. 2017, 56:1065-70. 10.1111/ijd.13685

6. Lopes RD, Alexander JH, Al-Khatib SM, et al.: Apixaban for Reduction In Stroke and Other ThromboemboLic Events in Atrial Fibrillation (ARISTOTLE) trial: design and rationale. Am Heart J. 2010, 159:331-9. 10.1016/j.ahj.2009.07.035

7. Eikelboom JW, Connolly SJ, Brueckmann M, et al.: Dabigatran versus warfarin in patients with mechanical heart valves. N Engl J Med. 2013, 369:1206-14. 10.1056/NEJMoa1300615

8. Yu WY, Bhutani T, Kornik R, Pincus LB, Mauro T, Rosenblum MD, Fox LP: Warfarin-associated nonuremic calciphylaxis. JAMA Dermatol. 2017, 153:309-14. 10.1001/jamadermatol.2016.4821

9. January CT, Wann LS, Calkins H, et al.: 2019 AHA/ACC/HRS focused update of the 2014 AHA/ACC/HRS Guideline for the Management of Patients With Atrial Fibrillation: a report of the American College of Cardiology/American Heart Association Task Force on Clinical Practice Guidelines and the Heart Rhythm Society in collaboration with the Society of Thoracic Surgeons. Circulation. 2019, 140:e125-e151. 10.1161/CIR.0000000000000665

10. Ezekowitz MD: Anticoagulation management of valve replacement patients . J Heart Valve Dis. 2002, 11:5660. 